\title{
A Novel Method for In Vitro 3D Imaging of Dissecting Pressurized Arterial Segments Using X-Ray Microtomography
}

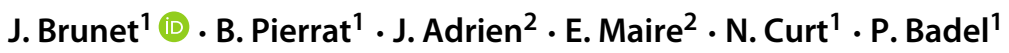 \\ Received: 30 December 2019 / Accepted: 21 July 2020 / Published online: 17 August 2020 \\ (C) The Author(s) 2020
}

\begin{abstract}
Background: It is commonly admitted that a dissection initiates with an intimal tear or at least a defect inside the arterial wall. Nevertheless, few studies investigated the initiation sequence due to the difficulty to monitor this process.

Objective: The objective of this work was to observe and investigate the mechanisms leading an intimal tear to propagate into a dissection.

Methods: A custom-made tension-inflation device fitting inside an X-ray microtomography setup was designed. A notch was created inside a porcine carotid artery before performing the tension-inflation test. The X-ray tomography setup allowed observing the wall-structure and the notch behavior during the inflation of the carotid artery.
\end{abstract}

Results: A quantitative description of the notch morphology was performed, suggesting the prevalence of high shear stress in the region of the crack tip as a possible trigger for propagation of a dissection.

Conclusions: The present experimental approach allowed understanding better the mechanisms leading to dissection and constitutes a first step toward the improvement of failure modeling and risk assessment of this disease.

Keywords Arterial dissection · Tension-inflation test · Microstructure $\cdot$ X-ray · Intimal tear $\cdot$ Fracture mechanics

\section{Introduction}

A major challenge in the vascular biomechanical field is the understanding of damage and rupture properties in arteries. This understanding is limited by the complexity of arterial microstructure. Several approaches were used to investigate the mechanisms behind these complex and nonlinear events. Most of these studies measured properties at the macro-scale in order to develop continuum constitutive models $[29,36,39]$. Nevertheless, the understanding of the microstructure influence seems to be the key to evidence the phenomena leading to rupture and to propose appropriate modeling approaches. In that purpose, studies combining

J. Brunet

jo.brunet73@gmail.com

1 Mines Saint-Etienne, Univ Lyon, Univ Jean Monnet, INSERM, U 1059 Sainbiose, Centre CIS, F - 42023 Saint-Etienne, France

2 INSA-Lyon, Université de Lyon, MATEIS CNRS UMR5510, Villeurbanne, France mechanical loading and microstructural observations are crucial to investigate damage propagation in arteries.

Aorta and major proximal arteries are composed of three layers. The innermost layer, called intima, is mainly composed of endothelial cells, making contact with the blood. The media is the middle layer, composed of several musculo-elastic unit separated by elastin laminae [10]. The outermost layer is the adventitia, mainly composed of collagen. It has a significant role in the stability and ultimate strength of the artery. Aortic dissection is characterized by a sudden delamination of the aortic wall, occurring in the medial layer. It is a life threatening condition with high mortality rate $[26,32]$. This event can be separated in two different mechanisms: initiation and propagation. In the majority of cases aortic dissection initiates with an intimal tear which propagates through the medial layer, hence allowing blood to flow in a false lumen. Nevertheless, intramural bleeding can also cause aortic dissection as no communication is found between these two lumina in $4 \%$ to $13 \%$ of aortic dissections $[14,19]$. Usually, the intimal tear is believed to be in a radial-circumferential plane $(\simeq 80 \%$ of cases) and involves more than half the circumference of 
the aorta [40]. There is a lack of understanding concerning the phenomena behind the tear propagation. For more information on aortic dissection see, for instance, the review by Brunet et al. [5].

Several experimental studies investigated the behavior of arterial wall related to dissection: liquid infusion test [7, $33,38,41]$, radial tensile test $[24,36]$, peeling test $[29,36$, 42], shear test [16, 17, 37, 48]. Although these mechanical tests allowed characterizing the rupture properties of arterial tissue, there is a lack of understanding on the early stages of aortic dissection, especially at the microstructural scale. The tension-inflation test is closer to in vivo conditions and was performed in multiple experimental studies to create an in vitro dissection [9, 13, 15, 30, 44]. Nevertheless, one of the difficulties with the investigation of dissection is that it is an intramural process which complicates observation. Combining the tension-inflation test with an appropriate imaging technique would overcome that issue and allow observing and quantifying the different steps of aortic dissection, especially in the early stages.

Different imaging techniques were used to observe arterial tissue. However, few were used in combination with mechanical tests. Recently multiphoton microscopy was often used to image arterial tissue as it allows observing collagen and elastin fibers. These studies investigated the organisation of collagen fibers structure inside the arterial wall during uniaxial and biaxial loading tests [8, 22, 47]. Although this approach provides many insights into the behavior of arterial wall at a micro-scale, the limited volume of observation $\left(<1 \mathrm{~mm}^{3}\right)$ is a major limitation in the observation of aortic dissection. X-ray microtomography (micro-CT) is an alternative non-destructive imaging method with a larger field of view $\left(1-10 \mathrm{~mm}^{3}\right)$. This technique allows observing the 3D microstructure of soft tissue with high resolution [25, 46]. However, in situ tests on soft tissues like arteries are still scarce in the literature. In a previous study, Helfenstein-Didier et al. [18] performed in situ uniaxial tensile tests on medial layer strips of porcine thoracic aorta inside a micro-CT setup with a resolution of $4 \mu \mathrm{m}$ to investigate the damage initiation and propagation mechanisms. Sodium polytungstate was used as a contrast agent to observe the musculo-elastic units of the media. The results highlighted the importance of the shear delamination of the medial layers in the failure process. This conclusion was supported by histological observations on the ruptured samples. Similar observations were also presented in the study of Sherifova et al. [34] which concluded that the microstructure and especially the collagen fiber architecture but also the different types of cross-links are of first importance in the uniaxial failure of soft tissues. In another in situ study using microCT, Trachet et al [43] performed tension-inflation test on mice left common carotid arteries, using synchrotronbased phase-contrast imaging. High resolution images of the carotid artery were obtained with a resolution of $1.625 \mu \mathrm{m}$, allowing the elastic lamellae to be segmented. The results showed that the lamellae stretch simultaneously as luminal pressure increases.

In the present work, an in vitro dissection was created and observed by combining a tension-inflation test with micro-CT. A notch was created inside the porcine common carotid artery to initiate the dissection. The structure of the artery was observed while performing the mechanical test by designing a custom-made device fitting inside a micro-CT setup. The objective was to follow-up the notch evolution during the inflation and investigate the damage propagation in the medial layer.

\section{Material and Method}

\section{Sample Preparation}

Porcine hearts with aorta and carotid arteries from 6month-old pigs were purchased from a local butchery few hours after death. Common carotid arteries were carefully excised and $50 \mathrm{~mm}$ long samples were cut. Pig was chosen as the arterial diameter and medial lamellae number are close to human [11] and suitable for a good compromise resolution/field of view with the micro-CT equipment used here. The present study aims at demonstrating the capacity of the experiment and its relevance in analysing early dissection progress, the results of two samples are presented. The first sample (sample 1) reached complete dissection prematurely, and could only be observed in the dissected state. The second sample (sample 2), analyzed in this paper, was followed up to a pressure that was not sufficient to fully propagate dissection.

\section{Contrast agent}

A major issue with arterial tissues and soft tissues in general is that the images obtained by micro-CT do not exhibit sufficient absorption contrast [27]. One solution to overcome this problem is to use synchrotron-based phase-contrast imaging as demonstrated by Logghe et al. [23]; however, access to this type of equipment is rare. In this work, a conventional micro-CT equipment was used in combination with a contrast agent binding with some components of the tissue to increase their absorption. Immediately after collection, the samples were immersed in a diluted solution of sodium polytungstate $(15 \mathrm{~g} / \mathrm{L})$ and placed in the fridge during 24 hours at $4{ }^{\circ} \mathrm{C}$. The immersion time of the sample ensuring a full penetration of 
the contrast agent in the tissue was adjusted in a previous study [18]. According to the same study, this contrast agent allowed observing the elastin sheets of the medial layer without significantly affecting the characterized mechanical properties of the tissue. The interest in using sodium polytungstate relies on the fact that there is no need of dehydration of the sample during the staining process to obtain sufficient contrast. Dehydration would affect the structure of the sample and deteriorate the mechanical properties.

\section{Notch creation}

In order to cause and observe a dissection propagating within the field of view, a custom device was designed to create a longitudinal notch inside the carotid artery without opening it (Fig. 1). The system was composed of a surgical scalpel blade of $8 \mathrm{~mm}$ length and $2 \mathrm{~mm}$ depth, attached to a rod to be inserted in the artery, itself guided vertically by linear ball bearings. To create the notch, the controlled device was used to cut through the intima and part of the media. The defect was created in the radiallongitudinal plane and not in the radial-circumferential plane due to technical difficulties. Although, intimal tears in the transverse direction are reported to be more common in the literature, the crack is seldom entirely in the radial-circumferential plane and often has a longitudinal component [12]. An optical coherence tomography (OCT) image of the notched carotid artery is shown in Fig. 2. This optical technique was used to adjust and assess the notch depth in a preliminary study. To this aim, four carotid arteries were harvested on pigs from the local butchery,

Fig. 1 The custom-made device to create the notch inside the carotid artery with a schematic of the cutting process

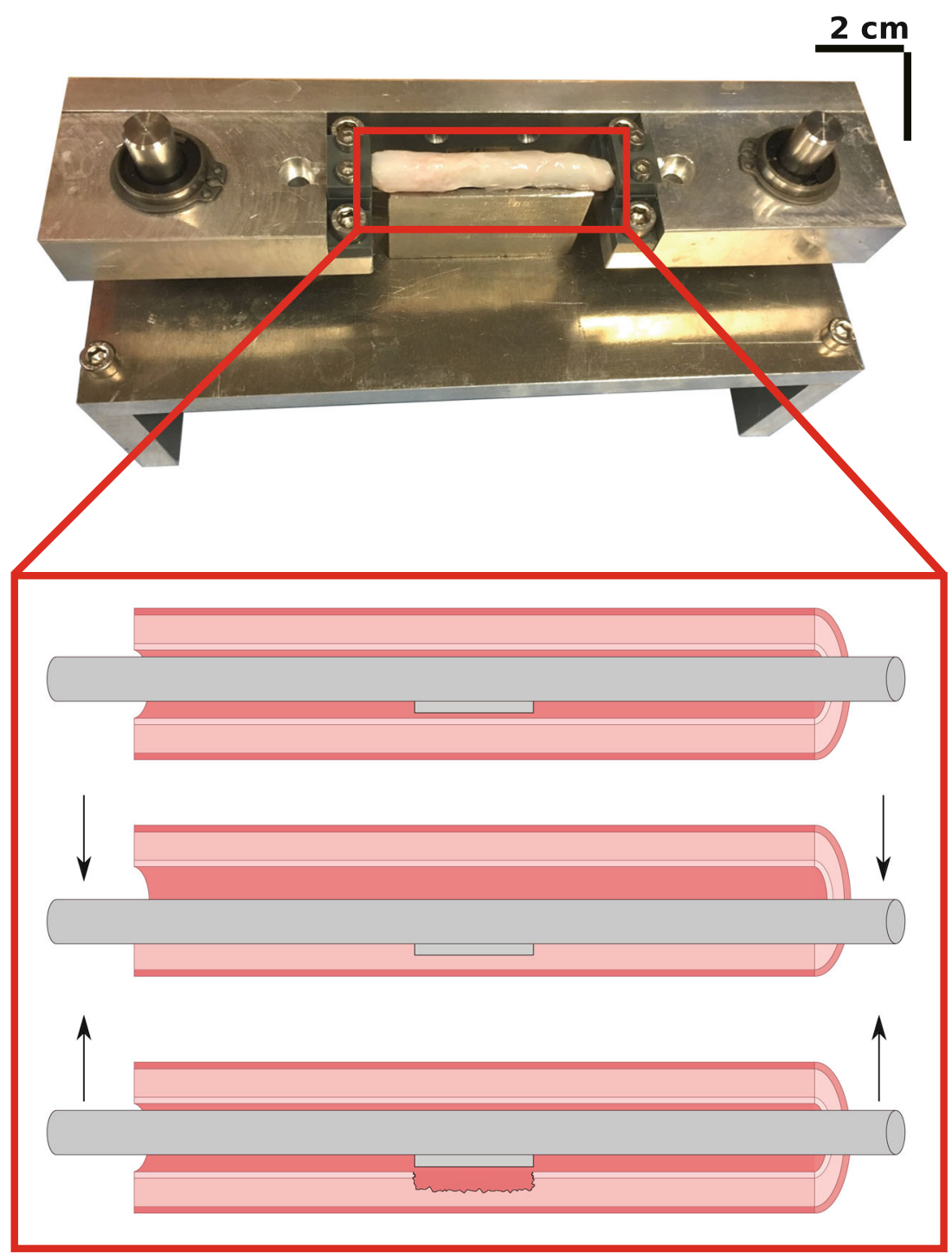


Fig. 2 OCT image of a flatopened carotid wall with a notch created by the cutting device

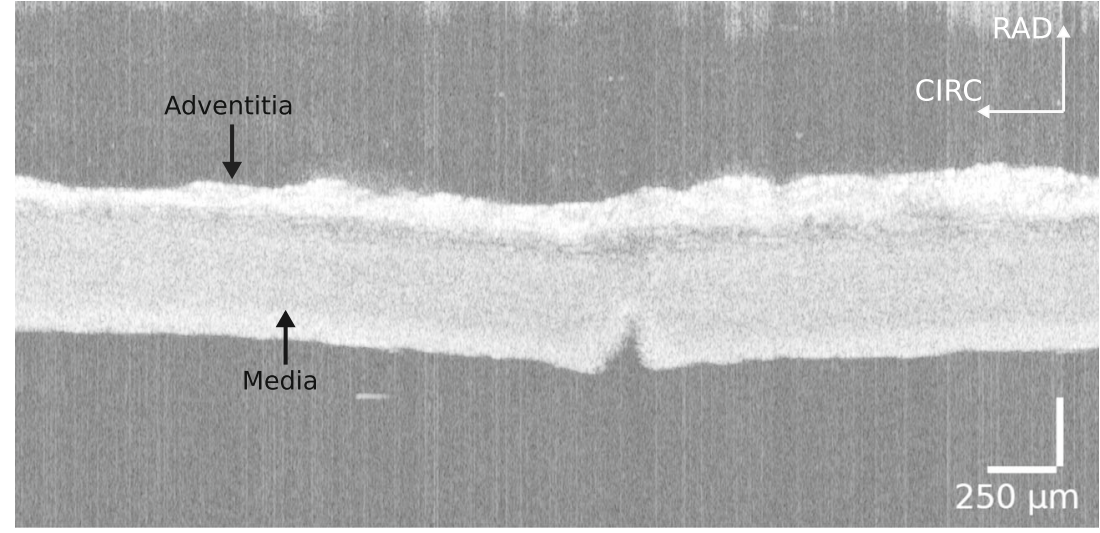

3 specimens with a length of $1.75 \mathrm{~mm}$ were cut from each carotid artery. A longitudinal notch was made in each specimen with the machine. Finally, the samples were opened and the 12 notches were observed and measured using OCT, it showed that the notch depth had a value of $263 \pm 83 \mu \mathrm{m}(\mathrm{n}=12)$. Though these results present a large variability, it must be noted that the exact notch depth will be measured in the micro-CT images of the subsequent tension-inflation test.

\section{Tension-Inflation Device}

\section{Mechanical setup}

A custom-made tension-inflation machine was designed to fulfil the constraints of the experiments planned in the study (Fig. 3). The main constraint was to fit the machine inside the micro CT equipment. To this aim the test was performed in a $50 \mathrm{~mm}$ diameter cylindrical PMMA tube, constituting the machine structure between both ends of the sample, to not interfere with the X-rays passing through and allow rotation of the whole machine. A motorized worm gear was used to apply displacement to the lower end of the sample with a maximum displacement of 50 $\mathrm{mm}$ and a maximum displacement rate of $1.25 \mathrm{~mm} / \mathrm{s}$. Through the upper end, a peristaltic pump quasi-statically infused a saline solution to increase the pressure inside the sample. A load sensor (LCM201, Omega ${ }^{T M}, \pm 300$ $\mathrm{N})$ and a pressure sensor (PXM319, Omega ${ }^{T M} 0$ - 3.5 bar) recorded the load and pressure all along the test. The device was fixed on the micro-CT rotating platform by screws. A custom-made program was developed to control the

Fig. 3 (a) Photo and (b) schematic of the custom-made tension-inflation device inside the micro-CT equipment
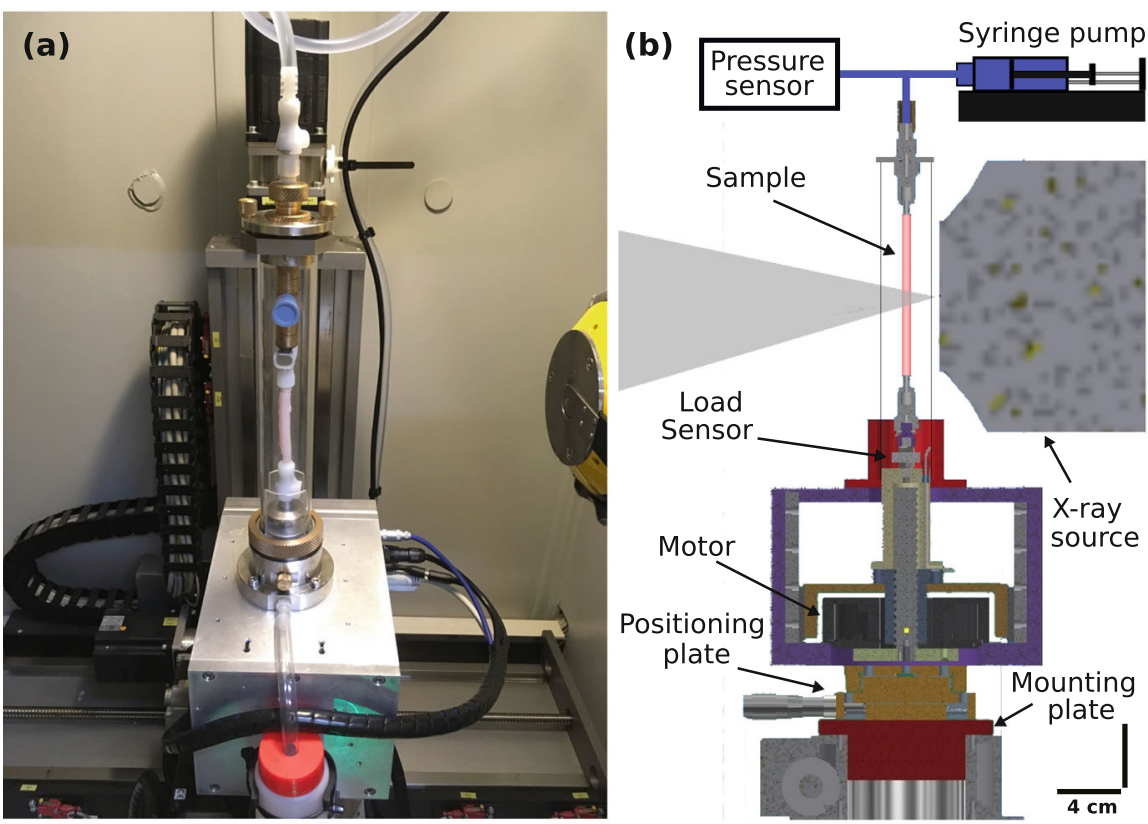
machine. Displacement- or load-controled and pressure- or volume-controled test could be performed in order to test a wide range of biaxial states. In the present study, the experiments were driven in displacement and pressure. To prevent dehydration of the sample during the test the tube was filled with steam by a humidifier. Previous tests with a humidity sensor (DHT22) showed that the atmosphere inside the tube was saturated.

\section{X-ray tomography setup}

$\mathrm{X}$-ray computed tomography is a non-destructive technique that allows the $3 \mathrm{D}$ reconstruction of a sample. It is widely used in both industrial and medical fields. The principle is based on the attenuation of X-rays by matter and their recording by an X-ray detector after going through the sample. Several views are taken at different angles and mathematical methods allow the 3D geometry and the internal structure to be reconstructed. For more information on X-ray tomography principle see Baruchel et al. [3].

In this study a Phoenix ${ }^{T M}$ VtomeX tomograph equipped with a Varian ${ }^{T M}$ Paxscan X-Ray detector was used, featuring a resolution of 1920 x 1536 pixels. The X-ray source was supplied with a voltage of $80 \mathrm{kV}$ and a current of $280 \mu \mathrm{A}$. The voxel size was $7 \times 7 \times 7 \mu \mathrm{m}^{3}$. No physical filters were used during the acquisition. Soft tissues are not as stable as hard tissues during the mechanical test with possible motion of the sample due to creep and stress relaxation resulting in a blurry image. To avoid these effects, a fast acquisition was needed and a compromise between resolution and scan time was made. The projection number was 800 and the total acquisition time was 266 seconds.

\section{Protocol}

After staining, the notched sample was ligatured to the tension-inflation device. An initial high resolution scan was performed in the unloaded configuration. Then, a physiological stretch of $\lambda_{z}=1.5$ was applied [31]. Once the stretch was applied, another scan was performed, followed by infusion at a rate of $0.026 \mathrm{~mL} / \mathrm{s}$. Pre-conditionning was not performed as it could trigger the propagation. 3D scans were acquired after reaching given pressure steps and allowing a relaxation time (5 to 10 minutes to stabilize the sample before imaging). The steps were set at 15,80 , $130,315,485,620,730 \mathrm{mmHg}$. At each pressure step a relaxation of the carotid artery was observed. After 10 minutes, when the pressure was considered stable, the scan was performed. The mean pressures present in the sample during the scans are reported in Table 1.
Table 1 Pressure targeted during the inflation and the actual mean pressure obtained after relaxation during the scan

\begin{tabular}{ll}
\hline Pressure target $(\mathrm{mmHg})$ & Scan pressure $(\mathrm{mmHg})$ \\
\hline 15 & 10 \\
80 & 59 \\
130 & 103 \\
320 & 301 \\
485 & 436 \\
620 & 590 \\
730 & 687 \\
\hline
\end{tabular}

\section{Post-Processing}

\section{Measure of diameter and thickness}

To measure the diameter of the vessel at the different pressure steps, the inner contour of the arterial wall was segmented, and an ellipse was fitted on it. The mean between the major and the minor axes was taken as the diameter of the lumen.

The medial thickness was measured manually at 10 random locations along the vessel. The adventitial thickness could not be measured as the delimitation between the adventitial layer and the connective tissue could not be determined clearly with the current resolution.

\section{Crack follow-up}

A semi-automatic method was developed to segment the notch on the X-ray images and, thus, follow its evolution with the pressure increase. A median filter was applied to reduce noise followed by a threshold applied to differentiate the wall from the solution inside the carotid artery. Different morphological operations were performed to remove spurious islands and holes, and the separation between the lumen and the notch was drawn manually. Finally, the notch could be segmented and several parameters were calculated like its width, depth, and volume.

\section{Wall integrity follow-up}

To follow the possible propagation into a dissection, which could be detected in the images, the histogram of the gray values along the radial direction was plotted at different locations in the cross-section corresponding to the maximum notch depth (Fig. 4): one next to the notch and ten far from it (in a region assumed to be 


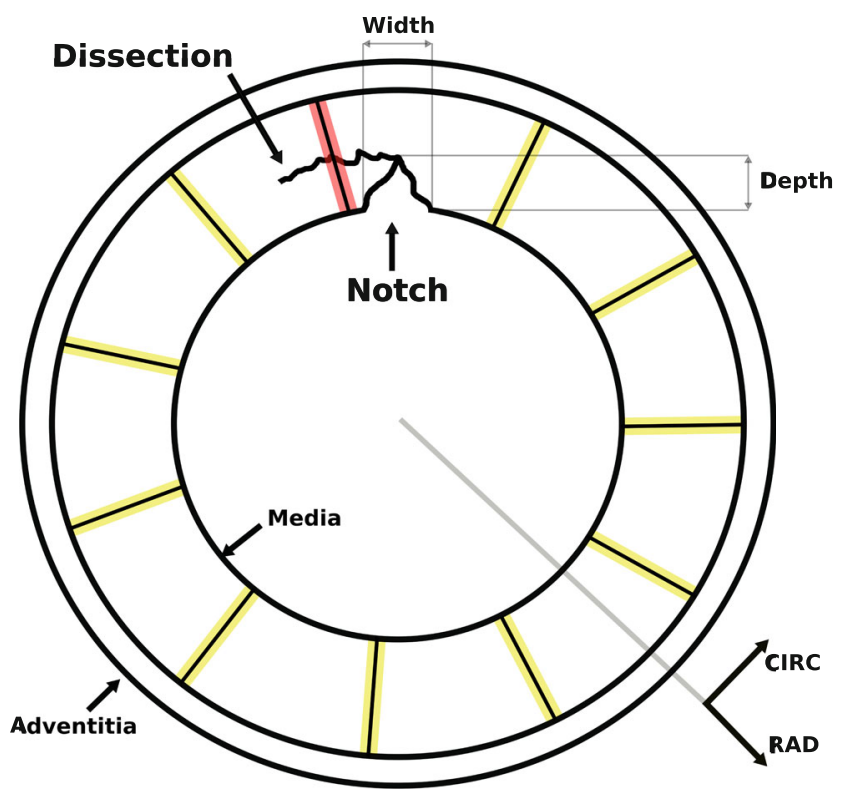

Fig. 4 Schematic representing a cross-section of the vessel with a dissection at the tip of the notch. The different locations where the histograms were plotted are shown with radial lines. The profiles are represented in red for the one measured close to the notch and in yellow for the ones measured far from it

perfectly non-damaged). To diminish the noise and avoid wall heterogeneities, at each point on the radial profile the value taken was the mean of the gray values of a square of $20 \times 20$ pixels. A decrease of the gray level at a given radial location means that the notch propagated in the form of a crack in the circumferential direction. This technique was complementary with the segmentation presented above as the algorithm had difficulty to segment micro-cracks.

\section{Results}

The reconstructed 3D images of the carotid artery showed clearly the media and the notch. Nevertheless, the medial lamellae could not be distinguished in all scans with the current resolution. As stated in the "Sample Preparation", only sample 2 was quantitatively analyzed in the present study. The results of the prematurely-dissected sample 1 are displayed at the end of this section. Concerning sample 2 , the scan in the unloaded configuration showed that the initial inner diameter and medial thickness of the specimen were $4.4 \mathrm{~mm}$ and $1.1 \mathrm{~mm}$ respectively. Cross-sectional views at the middle of the axially stretched sample are shown in Fig. 5 at different pressures. The evolution of the notch geometry is visible.

The notch was segmented at the different pressure steps and different information were extracted and displayed in Fig. 6. Figire 6a shows a 3D view of the segmented notch. Figure $6 \mathrm{~b}$ shows a view in the transverse plane at $30 \%$ of the height of the notch. The crack follows the stretch of the wall; however, no propagation could be observed on the segmented images. The width and the depth of the notch were plotted in Fig. 6c and in Fig. 6d respectively. The decrease of notch height between 103 and $301 \mathrm{mmHg}$ is explained by the imprecision of the segmentation method on the edges of the notch, especially at high pressures. The segmentation was also challenging for the lowest pressure as the notch was almost not visible because of the absence of pressure. The blade is curved on its edges to avoid stress concentration, explaining that the length of the notch was smaller than the blade length. This sample had an initial maximal notch depth of $182 \mu \mathrm{m}$, in the very low
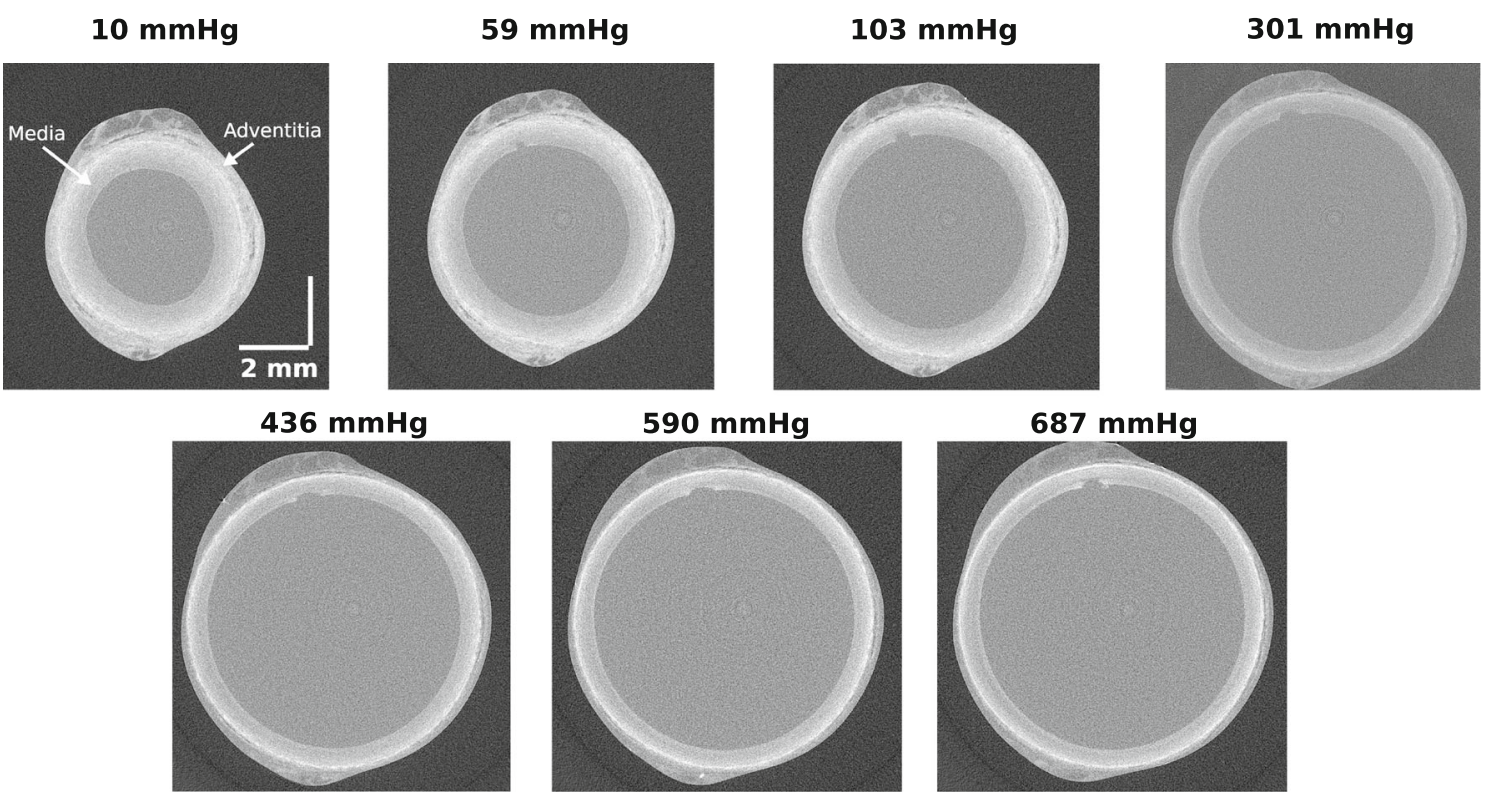

Fig. 5 Cross sectional views of the carotid speciment (sample 2) at a stretch of 1.5 and at the different pressure steps 
Fig. 6 Evolution of the notch morphology (sample 2). (a) A $3 \mathrm{D}$ view of the notch at the different pressure steps. (b) Cross-section of the notch at $30 \%$ of the height of the sample. (c) The width of the notch. (d)

The depth of the notch (a)

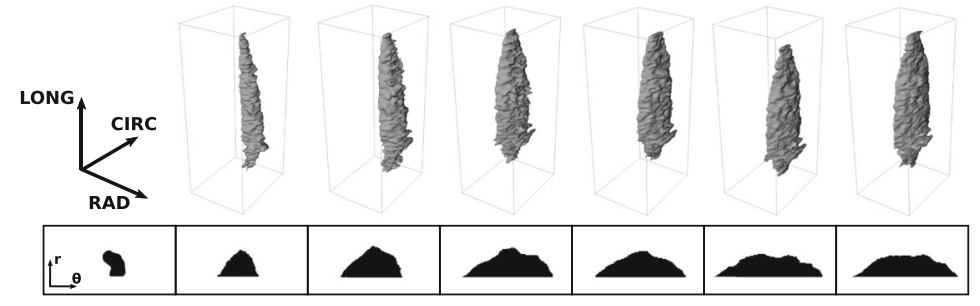

(b)

(c)

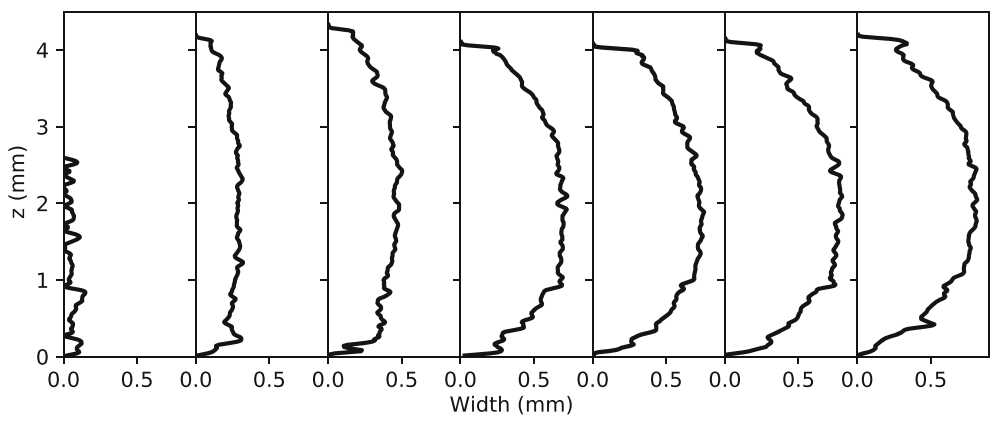

(d)

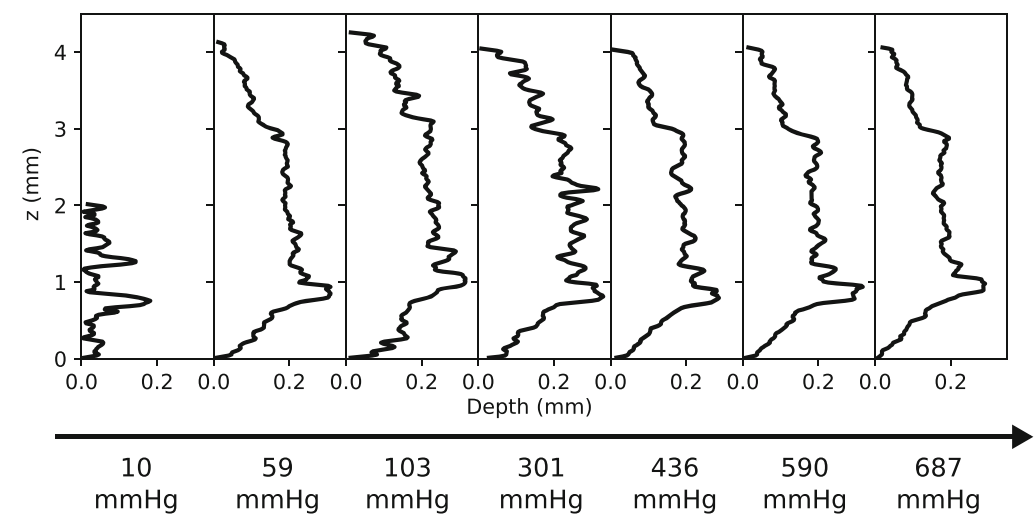

range of usual notch depth created with our setup, likely explaining why complete dissection was not reached with our pressurization setup.

Figure $7 \mathrm{a}$ presents the mean axial loading at each pressure steps. Figure 7b, c and d show the inner diameter, the medial thickness, and the notch volume respectively. The latter markedly increased for low pressures and became relatively constant after, similarly to the inner diameter, and inversely to the medial thickness. It is interesting to note that the maximum variation of the lumen diameter along the vessel for all pressure steps was equal to $50 \mu \mathrm{m}$.

On the graph Fig. 8, the arrow shows the presence of a micro-crack in the circumferential direction near the notch. This crack appeared on the images at $301 \mathrm{mmHg}$ and continued to be visible for higher pressures.

A cross section view of the prematurely-dissected sample 1 is shown in Fig. 9. The initial inner diameter and the medial thickness of the specimen were $4.2 \mathrm{~mm}$ and $1.1 \mathrm{~mm}$ respectively. During the test, the media ruptured entirely; however, the adventitia was unruptured. The notch propagated on more than half the circumference of the artery and a considerable circumferential elastic recoil of the media was observed. The arrows highlight the presence of delamination planes at the rupture site.

\section{Discussion}

This paper presented a novel experimental approach to study the mechanical events involved in the propagation of arterial dissection. In situ testing combining tension-inflation test with micro-CT allowed observing the internal structure of notched carotid arteries as an in vitro model of dissection.

In the present context, the main advantage of this imaging technique is to offer a suitable resolution/field of view compromise to enable both a global observation of the damage site (here, the notch) and lamellar-scale details such as intramural dissection planes which were evidence here around the notch. The deformation of the notch volume with the pressure followed the deformation of the wall. This is shown by the similar shape of the pressure-diameter curve (Fig. 7b) and the pressure-notch volume curve (Fig. 7d). 
Fig. 7 (a) Axial load, (b) inner diameter, (c) medial thickness, (d) notch volume as a function of pressure (sample 2)
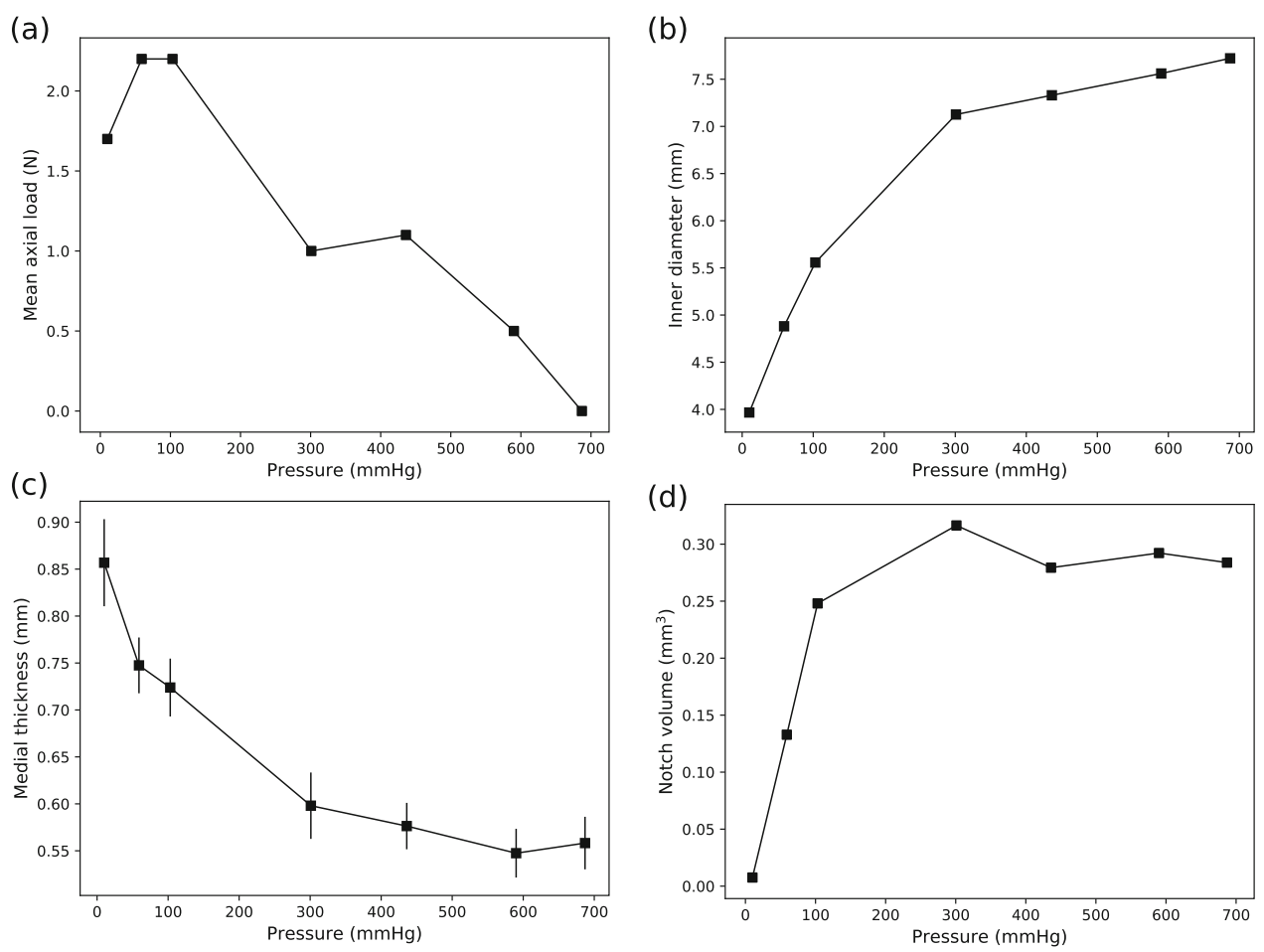

This can also be seen by the evolution of the notch shape Fig. $6 \mathrm{~b}$ where the notch flattened and became relatively stable after $301 \mathrm{mmHg}$. The absence of propagation of the notch is rather clear in one of our experiment. This could be explained by the lack of medial degeneration in the sample,

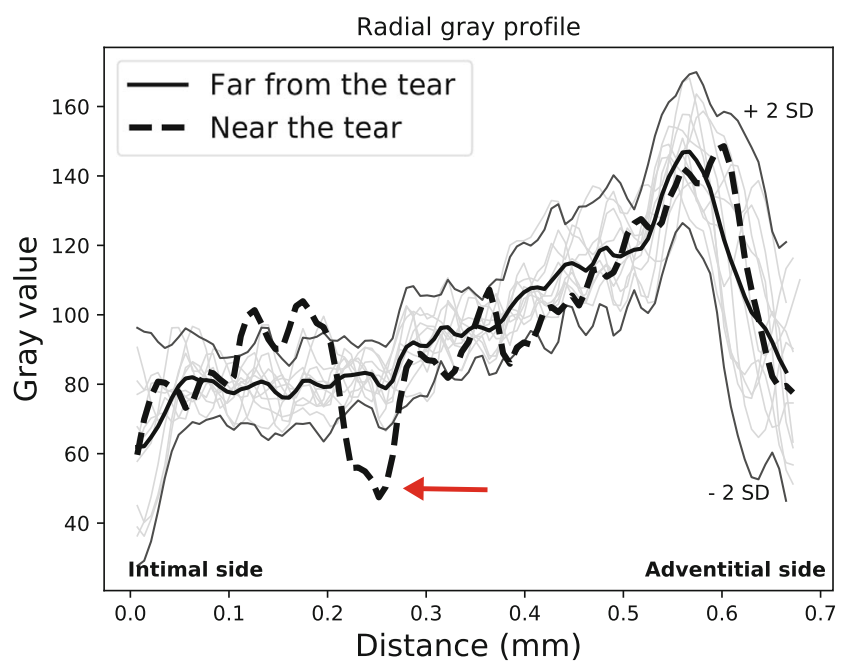

Fig. 8 Radial gray values profile at $301 \mathrm{mmHg}$ in the cross-section corresponding to the maximum notch depth at different locations of the arterial wall (sample 2). The thick dash curve corresponds to the measure close to the notch. The thick solid curve characterizes the mean of the profiles measured far from the notch. The curves representing the mean \pm 2 standard deviations (SD) were also plotted. The arrow shows a decrease in gray values close to the notch compared to the normal profile in the healthy part of the sample, demonstrating the presence of early crack propagation which is usually considered as one of the main causes of aortic dissection. Nevertheless, aortic dissection can be triggered by a supra-physiological blood pressure (during weighlifting for instance [35]), meaning that maximum

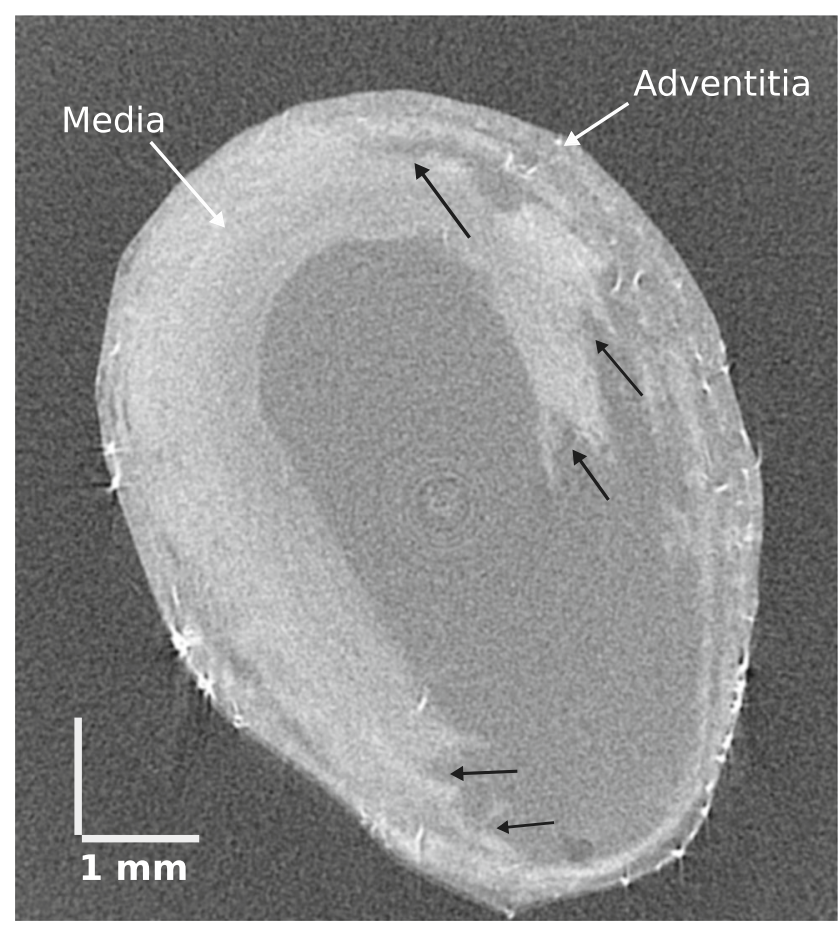

Fig. 9 Cross-section of the dissected specimen (sample 1). The arrows indicate delamination planes 
pressure may play a role in aortic dissection. Concerning the axial load, multiple factors could explain the decrease observed in Fig. 7a, for instance the axial pre-stretch being slightly lower than the actual in vivo stretch $[2,21]$. The inner diameter measured during the experiment is consistent with the results found in the literature from tension-inflation test on healthy carotid arteries $[4,45]$. In our experiment, the notch did not seem to affect the diameter as there were almost no variations in the inner diameter along the vessel; however, the depth of the notch was limited, which could explain this result.

During the inflation of the carotid artery, at the tip of the notch, a high tension stress is present in the remaining intact medial lamellae, and hence a high shear stress between intact and ruptured lamellae. The propagation of the notch in the circumferential direction, observed in Fig. 8, can be hypothesized to be a consequence of this local stress state, indicating the importance of shear delamination in dissection propagation. The same observation was made by Haslach et al. [17], where bovine aortic rings with a longitudinal notch on the intimal side were inflated until failure. The propagation of the crack occurred nearly in the tangential plane and the authors concluded that it was a consequence of the shear deformation present inside the wall during inflation. This conclusion is supported by the study of Witzenburg et al. [48] which demonstrated the very low interlamellar strength of arterial tissue, especially against shear stress. Other studies used uni-axial test to highlight the importance of shear delamination stress in the failure process $[18,34]$. Using histology, these studies observed delamination planes at the rupture zone, similarly to the observation made in Fig. 9. This confirms the presence of shearing mechanisms during the propagation of the dissection in the tension-inflation test. HelfensteinDidier et al. [18] also identified a pattern of rupture during uniaxial tension tests on medial samples. The results showed that an elementary rupture sequence repeated until complete failure: a bunch of musculo-elastic units breaks in tension (mode I), followed by a delamination (mode II) of this layer from the wall. Based on these observations, [6] showed that shear delamination strength is most likely the predominant factor in the initiation of dissection. The Fig. 9 seems to exhibit a similar failure sequence, the presence of multiple delamination planes indicates that several bunches of musculo-elastic units broke and started to delaminate from the arterial wall. At one point, the delamination shear stress between lamellae created by this mechanical state overcame the interlamellar strength and the crack propagated in the tangential plane in mode II delamination. Nevertheless, the second test did not reach failure due to low notch depth and could not confirm these observations; thus, further tests are needed.
The majority of aortic dissections involve more than half of the circumference of the aorta [40]. The same phenomenon was observed on the X-ray images of the present study (Fig. 9), confirming that the in vitro dissection obtained during the experiment is similar to those seen in clinic. Furthermore, the dissection propagated up to the boundary between media and adventitia, as described in experimental studies where the dissection is shown to propagate in the outer media $[1,28]$. The fact that the adventitia was unruptured illustrates its protective role for the artery. Holzapfel et al [20] showed that the residual stress present in the arterial wall is layer-dependent and that the media, once separated from the other layers, shortens significantly. Thus, the elastic recoil of the medial layer observed in this sample is explained by the release of its tension stress initially present when the carotid artery was intact.

This work demonstrated the feasibility and relevance of the proposed experimental approach; however, the following limitations should be mentioned. First, in clinics most of the intimal tears encounter are in the transverse plane. The notch in the present study was made longitudinal as it simplified the identification of the fracture modes involved in the propagation of the dissection. In future work, we could perform this test with a transverse intimal notch to compare the influence of the notch direction on the propagation, or absence of propagation, of the defect. Another limitation is that the separation between the adventitia and the connective tissue during the preparation of the sample is complicated as there is a continuity between the two in this type of tissue. Further analysis could address the question of preferred propagation direction or fracture modes involved. Other interesting perspective might be to apply volume correlation analysis to quantify the strain of the arterial wall at different steps of the dissection; thus, these data could be used to validate complex model involving damage and rupture.

\section{Conclusion}

In conclusion, an experimental approach was presented to create an in vitro dissection model and observe it with micro-CT. This experimental approach allowed following the deformation of a notch and investigating the early stages of dissection propagation. The micro-CT images highlight the importance of shear delamination strengh during the propagation of the dissection. In situ testing associated with $\mathrm{X}$-ray microtomography is a promising way to assess the mechanisms leading to rupture in biological tissue.

Acknowledgments This work was supported by the European Research Council through Starting Grant AArteMIS n ${ }^{\circ} 638804$. 


\section{Compliance with Ethical Standards}

Conflict of interests The authors declare that they have no conflict of interest.

Open Access This article is licensed under a Creative Commons Attribution 4.0 International License, which permits use, sharing, adaptation, distribution and reproduction in any medium or format, as long as you give appropriate credit to the original author(s) and the source, provide a link to the Creative Commons licence, and indicate if changes were made. The images or other third party material in this article are included in the article's Creative Commons licence, unless indicated otherwise in a credit line to the material. If material is not included in the article's Creative Commons licence and your intended use is not permitted by statutory regulation or exceeds the permitted use, you will need to obtain permission directly from the copyright holder. To view a copy of this licence, visit http:// creativecommonshorg/licenses/by/4.0/.

\section{References}

1. Angouras DC, Kritharis EP, Sokolis DP (2019) Regional distribution of delamination strength in ascending thoracic aortic aneurysms. J Mech Behav Biomed Mater

2. Avril S, Badel P, Gabr M, Sutton MA, Lessner SM (2013) Biomechanics of porcine renal arteries and role of axial stretch. J Biomech Eng 135(8)

3. Baruchel J, Buffiere JY, Maire E (2000) X-ray tomography in material science. Hermes Science Publications

4. Boekhoven RW, Peters MF, Rutten MC, van Sambeek MR, van de Vosse FN, Lopata RG (2016) Inflation and bi-axial tensile testing of healthy porcine carotid arteries. Ultrasound Med Biol 42(2):574-585

5. Brunet J, Pierrat B, Badel P (2020) Review of current advances in the mechanical description and quantification of aortic dissection mechanisms. IEEE Rev Biomed Eng

6. Brunet J, Pierrat B, Maire E, Adrien J, Badel P (2019) A combined experimental-numerical lamellar-scale approach of tensile rupture in arterial medial tissue using $\mathrm{X}$-ray tomography. $\mathrm{J}$ Mech Behav Biomed Mater 95:116-123

7. Carson MW, Roach M (1990) The strength of the aortic media and its role in the propagation of aortic dissection. J Biomech 23(6):579-588

8. Cavinato C, Helfenstein-Didier C, Olivier T, Du Roscoat SR, Laroche N, Badel P (2017) Biaxial loading of arterial tissues with $3 \mathrm{~d}$ in situ observations of adventitia fibrous microstructure: a method coupling multi-photon confocal microscopy and bulge inflation test. J Mech Behav Biomed Mater 74:488-498

9. Chung JW, Elkins C, Sakai T, Kato N, Vestring T, Semba CP, Slonim SM, Dake MD (2000) True-lumen collapse in aortic dissection. Radiology 214(1):87-98

10. Clark JM, Glagov S (1979) Structural integration of the arterial wall. I. Relationships and attachments of medial smooth muscle cells in normally distended and hyperdistended aortas. Lab Invest 40(5):587-602

11. Clark JM, Glagov S (1985) Transmural organization of the arterial media. the lamellar unit revisited. Arterioscler Thromb Vasc Biol 5(1):19-34

12. Doroghazi RM, Slater EE (1983) Aortic dissection. McGraw-Hill Companies

13. Dziodzio T, Juraszek A, Reineke D, Jenni H, Zermatten E, Zimpfer D, Stoiber M, Scheikl V, Schima H, Grimm M et al (2011) Experimental acute type B aortic dissection: different sites of primary entry tears cause different ways of propagation. Ann Thorac Surg 91(3):724-727

14. Erbel R, Oelert H, Meyer J, Puth M, Mohr-Katoly S, Hausmann D, Daniel W, Maffei S, Caruso A, Covino F (1993) Effect of medical and surgical therapy on aortic dissection evaluated by transesophageal echocardiography. implications for prognosis and therapy. the european cooperative study group on echocardiography. Circulation 87(5):1604-1615

15. Faure EM, Canaud L, Cathala P, Serres I, Marty-Ané C, Alric P (2014) Human ex-vivo model of stanford type B aortic dissection. J Vasc Surg 60(3):767-775

16. Haslach HW Jr, Leahy LN, Fathi P, Barrett JM, Heyes AE, Dumsha TA, McMahon E (2015) Crack propagation and its shear mechanisms in the bovine descending aorta. Cardiovasc Eng Technol 6(4):501-518

17. Haslach HW Jr, Siddiqui A, Weerasooriya A, Nguyen R, Roshgadol J, Monforte N, McMahon E (2018) Fracture mechanics of shear crack propagation and dissection in the healthy bovine descending aortic media. Acta Biomater 68:53-66

18. Helfenstein-Didier C, Taïnoff D, Viville J, Adrien J, Maire E, Badel P (2018) Tensile rupture of medial arterial tissue studied by $\mathrm{x}$-ray micro-tomography on stained samples. J Mech Behav Biomed Mater 78:362-368

19. Hirst AE, Johns VJ, Kime SW (1958) Dissecting aneurysm of the aorta: a review of 505 cases. Med (Baltimore) 37(3):217

20. Holzapfel GA, Sommer G, Auer M, Regitnig P, Ogden RW (2007) Layer-specific 3d residual deformations of human aortas with non-atherosclerotic intimal thickening. Ann Biomed Eng 35(4):530-545

21. Humphrey J, Eberth J, Dye W, Gleason R (2009) Fundamental role of axial stress in compensatory adaptations by arteries. J Biomech 42(1): 1-8

22. Krasny W, Morin C, Magoariec H, Avril S (2017) A comprehensive study of layer-specific morphological changes in the microstructure of carotid arteries under uniaxial load. Acta Biomater 57:342-351

23. Logghe G, Trachet B, Aslanidou L, Villaneuva-Perez P, De Backer J, Stergiopulos N, Stampanoni M, Aoki H, Segers P (2018) Propagation-based phase-contrast synchrotron imaging of aortic dissection in mice: from individual elastic lamella to $3 \mathrm{~d}$ analysis. Sci Rep 8(1):2223

24. MacLean NF, Dudek NL, Roach M (1999) The role of radial elastic properties in the development of aortic dissections. J Vasc Surg 29(4):703-710

25. Mizutani R, Suzuki Y (2012) X-ray microtomography in biology. Micron 43(2-3):104-115

26. Nienaber CA, Clough RE, Sakalihasan N, Suzuki T, Gibbs R, Mussa F, Jenkins MP, Thompson MM, Evangelista A, Yeh JS et al (2016) Aortic dissection. Nat Rev Dis Primers 2:16053

27. Nierenberger M, Rémond $Y$, Ahzi S, Choquet $P$ (2015) Assessing the three-dimensional collagen network in soft tissues using contrast agents and high resolution micro-ct: application to porcine iliac veins. CR Biol 338(7):425-433

28. Osada H, Kyogoku M, Ishidou M, Morishima M, Nakajima $H$ (2012) Aortic dissection in the outer third of the media: what is the role of the vasa vasorum in the triggering process. Eur $\mathrm{J}$ Cardiothorac Surg 43(3):e82-e88

29. Pasta S, Phillippi JA, Gleason TG, Vorp DA (2012) Effect of aneurysm on the mechanical dissection properties of the human ascending thoracic aorta. J Thorac Cardiovasc Surg 143(2):460-467

30. Peelukhana SV, Wang Y, Berwick Z, Kratzberg J, Krieger J, Roeder B, Cloughs RE, Hsiao A, Chambers S, Kassab GS (2017) Role of pulse pressure and geometry of primary entry tear in acute type B dissection propagation. Ann Biomed Eng 45(3):592-603

31. Perrée J, van Leeuwen TG, Kerindongo R, Spaan JA, VanBavel E (2003) Function and structure of pressurized and perfused porcine 
carotid arteries: effects of in vitro balloon angioplasty. Am J Pathol 163(5):1743-1750

32. Rinaudo A, D'Ancona G, Lee JJ, Pilato G, Amaducci A, Baglini R, Follis F, Pilato M, Pasta S (2014) Predicting outcome of aortic dissection with patent false lumen by computational flow analysis. Cardiovasc Eng Techn 5(2):176-188

33. Roach M, Song S (1994) Variations in strength of the porcine aorta as a function of location. Clin Invest Med 17(4):308

34. Sherifova S, Sommer G, Viertler C, Regitnig P, Caranasos T, Smith MA, Griffith BE, Ogden RW, Holzapfel GA (2019) Failure properties and microstructure of healthy and aneurysmatic human thoracic aortas subjected to uniaxial extension with a focus on the media. Acta Biomater

35. Singh B, Treece JM, Murtaza G, Bhatheja S, Lavine SJ, Paul TK (2016) Aortic dissection in a healthy male athlete: a unique case with comprehensive literature review. Case Rep Cardiol 2016

36. Sommer G, Gasser TC, Regitnig P, Auer M, Holzapfel GA (2008) Dissection properties of the human aortic media: an experimental study. J Biomech Eng 130(2):021007

37. Sommer G, Sherifova S, Oberwalder PJ, Dapunt OE, Ursomanno PA, DeAnda A, Griffith BE, Holzapfel GA (2016) Mechanical strength of aneurysmatic and dissected human thoracic aortas at different shear loading modes. J Biomech 49(12):2374-2382

38. Tam AS, Sapp MC, Roach M (1998) The effect of tear depth on the propagation of aortic dissections in isolated porcine thoracic aorta. J Biomech 31(7):673-676

39. Teng Z, Tang D, Zheng J, Woodard PK, Hoffman AH (2009) An experimental study on the ultimate strength of the adventitia and media of human atherosclerotic carotid arteries in circumferential and axial directions. J Biomech 42(15):2535-2539

40. Thubrikar M, Agali P, Robicsek F (1999) Wall stress as a possible mechanism for the development of transverse intimal tears in aortic dissections. J Med Eng Technol 23(4):127-134
41. Tiessen I, Roach M (1993) Factors in the initiation and propagation of aortic dissections in human autopsy aortas. J Biomech Eng 115(1):123-125

42. Tong J, Sommer G, Regitnig P, Holzapfel GA (2011) Dissection properties and mechanical strength of tissue components in human carotid bifurcations. Ann Biomed Eng 39(6):1703-1719

43. Trachet B, Ferraro M, Lovric G, Aslanidou L, Logghe G, Segers P, Stergiopulos N (2019) Synchrotron-based visualization and segmentation of elastic lamellae in the mouse carotid artery during quasi-static pressure inflation. JR Soc Interface 16(155): 20190179

44. Tsai TT, Schlicht MS, Khanafer K, Bull JL, Valassis DT, Williams DM, Berguer R, Eagle KA (2008) Tear size and location impacts false lumen pressure in an ex vivo model of chronic type B aortic dissection. J Vasc Surg 47(4):844-851

45. Vychytil J, Moravec F, Kochová P, Kuncová J, Švíglerová J (2010) Modelling of the mechanical behaviour of porcine carotid artery undergoing inflation-deflation test. Appl Comput Mech 4(2):251-262

46. Walton LA, Bradley RS, Withers PJ, Newton VL, Watson RE, Austin C, Sherratt MJ (2015) Morphological characterisation of unstained and intact tissue micro-architecture by $\mathrm{x}$-ray computed micro-and nano-tomography. Sci Rep 5:10074

47. Wang R, Brewster LP, Gleason RL Jr (2013) In-situ characterization of the uncrimping process of arterial collagen fibers using two-photon confocal microscopy and digital image correlation. J Biomech 46(15):2726-2729

48. Witzenburg CM, Dhume RY, Shah SB, Korenczuk CE, Wagner HP, Alford PW, Barocas VH (2017) Failure of the porcine ascending aorta: multidirectional experiments and a unifying microstructural model. J Biomech Eng 139(3):031005

Publisher's Note Springer Nature remains neutral with regard to jurisdictional claims in published maps and institutional affiliations. 